\title{
Screening of high risk neonates for congenital heart defects: A study in level III neonatal intensive care unit
}

\author{
Devadas S. ${ }^{1}$, Gagandeep V.L. ${ }^{2}$, Nagabhushan B.M. ${ }^{3}$, Pavitra N.A. ${ }^{4}$, Ranjitha R. ${ }^{5}$, Pruthvi S. ${ }^{6}$ \\ ${ }^{1}$ Dr. Sahana Devadas, Associate Professor, ${ }^{2}$ Dr Vijayalaxmi Gagandeep, Assistant Professor, ${ }^{3}$ Dr. Nagabhushan BM, Post \\ Graduate, ${ }^{4}$ Dr. Pavitra N.A., Post Graduate, ${ }^{5}$ Dr. Ranjitha R, Post Graduate, above all authors are affiliated with \\ Department of Pediatrics, BMCRI, Bangalore, ${ }^{6}$ Dr. Pruthvi S, Post Graduate, Department of Community Medicine, \\ KIMS, Bangalore, India.
}

Address for Correspondence: Dr. Sahana Devadas, Email: sahanad28@gmail.com

\begin{abstract}
Introduction: Congenital heart defects are most common birth defects representing a major global health problem. So, early screening of high risk newborns for congenital heart defects is essential foe early intervention thereby help us to reduce morbidity and mortality. It is very important to screen all high-risk newborn for congenital heart defects, early identification and management to reduce mortality and morbidity in tertiary care neonatal intensive care unit. Pattern of CHDs is essential to predict management and outcome. Methods and Materials: A one year prospective study was carried out in a level III neonatal intensive care, Department of pediatrics, Bangalore Medical College and Research Institute, Bangalore, Karnataka, India, from October 2015 to September 2016. All high-risk newborns were screened for congenital heart defects through transthoracic 2D echocardiography. Patent foramen ovale in preterm was excluded. Retrospectively maternal risk factors were studied. Results: Total live births during the study period were 15127. And total admissions to our neonatal intensive care were 4531 cases. High-risk newborns screened for congenital heart defects are 1324 cases during the study period. Among 1324 newborns screened, 645 cases (49\%) were having CHDs, 679(51\%) were normal. Among CHDs 326 babies had ASD, 102 babies had VSD, 223 cases had PDA, and 35 cases had cyanotic congenital heart defects. Conclusions: Nearly half of the high risk newborns had CHD, thus it's very essential to screen them at the earliest. Majority of CHDs were cyanotic type of CHDs. Preterm babies, babies born to diabetic mothers and babies who had severe respiratory distress requiring prolonged ventilator support are highly prone for having underlying CHDs. Babies born to mothers who had antenatal folic acid supplementations were less likely to have CHDs.
\end{abstract}

Keywords: High risk newborns, Preterm, IDM, Congenital heart defects, Risk factors.

\section{Introduction}

Congenital heart defects are common among all birth defects [1]. Thus screening of CHDs for early detection and management is very important to improve outcome and reduce mortality and morbidity across and world. Study conducted in Europe showed heart defects constitutes for twenty eight percent of all birth defects. The worldwide prevalence of congenital heart defects estimated to be eight to ten per 1000 live births [2]. Several studies conducted in India have showed the prevalence between 2.5 to $13.6 / 1000$ live births $[3,4]$. CHDs are commonly seen in newborns, infants and school going age group. Late detection of CHDs in our country is also common. After the advent of Trans

Manuscript received: $16^{\text {th }}$ January 2017

Reviewed: $24^{\text {th }}$ January 2017

Author Corrected: $30^{\text {th }}$ January 2017

Accepted for Publication: $9^{\text {th }}$ February 2017 thoracic 2D echocardiography in India the data showing the prevalence of CHDs has drastically risen aised. In India still we have not achieved 100\% institutional deliveries and many peripheral hospitals are not having facilities to screen for CHDs. Hence screening of all high-risk newborns for detection of CHDs to know their profile and associated risk factors is very essential.

In most of studies conducted on pediatric age group was found that ventricular septal defect (VSD) is most common lesion followed by patent ductus arteriosus. The other common defects found are atrial septal defects (ASD), pulmonary stenosis (PS) and less number of cyanotic congenital heart diseases. A community based study conducted in Uttarkhand, India Bhat et al found VSD (30.4\%), ASD (17.63\%), PDA 
(9.62\%) and PS (6.4\%) [3]. More commonly associated risk factors for development of CHDs includes folic acid deficiency during preconception and during pregnancy, gestational and maternal diabetes mellitus, febrile illness during first trimester of pregnancy, consanguineous marriage, maternal drug exposure, maternal connective tissue disorders, bad obstetric history like unexplained still births, recurrent abortions, advanced parental age.

Need for the Study: Congenital heart defects accounts for good number of neonatal and infant deaths in our country. Since the average live births are very high compare to other countries the number of CHD cases will also be high [5]. CHDs are rarely screened routinely, identified and properly treated in our country.

The majority of CHDs during neonatal period will not get detected due to still high number of home deliveries, lack of awareness, poor socioeconomic status, and unavailability of 2D Echocardiography facilities at peripheral heath system. The present study was done at level III neonatal critical care unit where we screened all high-risk newborns for CHDs to know the profile of CHDs in newborn period and possible risk factors for development of CHDs. Hence early detection will have early planned management of CHDs and thus helping to reduce neonatal mortality secondary to CHDs.

\section{Methods and Material}

A one-year prospective study was carried out in a level III neonatal intensive care, Department of pediatrics, Bangalore Medical College and Research Institute, Bangalore, Karnataka, India, from October 2015 to September 2016.

We screened all high-risk newborns through Tran thoracic 2D echocardiography to study the profile of CHDs in newborn period and their possible risk factors associated for development of CHDs. Patent foramen ovale in preterm babies were excluded. The following newborn groups were screened for detection of congenital heart defects:

Preterm newborns: Any newborn baby born before 37 weeks of gestation with birth weight less than 1800 grams admitted in neonatal intensive care unit for preterm and low birth weight care and successfully discharged were included.

Infant of diabetic mother: Baby born to a known case of diabetic mellitus (fasting glucose $>126 \mathrm{mg} / \mathrm{dl}$ and post prandial $>200 \mathrm{mg} / \mathrm{dl}$ ) or gestational diabetes mellitus (GDM) i.e. carbohydrate intolerance of variability severity with onset or first recognition during the present pregnancy.

Fasting glucose level $>100 \mathrm{mg} / \mathrm{dl}$ and $<126 \mathrm{mg} / \mathrm{dl}$ are subjected for glucose tolerance test with $75 \mathrm{gms}$ of oral glucose, post oral glucose level of $>140 \mathrm{mg} / \mathrm{dl}$ are considered as gestational diabetes mellitus [6].

Bad obstetric history: mother who had history of previous 2 or more consecutive spontaneous abortions, stillbirths, intrauterine growth restriction, early neonatal death and/or congenitally malformed babies [7].

Severe respiratory distress at birth requiring mechanical ventilation support: Babies who had severe respiratory distress, clinically assessed with Downe's score and Silverman Anderson score requiring mechanical ventilation support at birth. After extubation from ventilatory support babies were screened for CHDs. Babies died on ventilator were not screened for CHD.

All babies who were screened for CHDs were asked about history of consanguineous marriage in parents and history of maternal fever in first trimester. Maternal preconception or antenatal consumption of folic acid was recorded.

All newborns suspected of CHDs in NICU, on the basis of clinical examination were also screened. A suspected case was defined as any newborn with $\mathrm{SpO}_{2}<87 \%$ in room air or visible cyanosis, feeding difficulty, unexplained congestive cardiac failure, murmur, abnormal heart sounds, differential saturation, differential peripheral pulses, abnormal blood pressures, abnormal chest $\mathrm{x}$-ray and abnormal electrocardiography (ECG).

Congenital heart defects detected during antenatal scans were excluded. After screening with 2D echocardiography, newborns that got detected to have CHD not normal 2D echocardiography were grouped. Babies who had CHDs were future studied for risk factors.

The risk factors analyzed were history of consanguinity, preterm babies, infants of diabetic mothers; babies who had significant respiratory distress requiring prolonged ventilator support, febrile illness during antenatal period, bad obstetric history, multivitamin and folic acid intake by mother. Spectrum of various CHDs was than analyzed. 


\section{Results}

A total of 1324 newborns were screened by 2D transthorasic echocardiography of which 645 (49\%) babies were detected to have CHD. Remaining 679 (51\%) babies were normal. Out of 645 CHD babies 344 were male babies, 301 were female babies. Among 645 CHDs only 35(5.4\%) cases were congenital cyanotic heart disease, rest $94.6 \%$ were congenital acyanotic heart disease. Majority of newborns had atrial septal defect (ASD) with 326(50.5\%) cases, followed by patent ductus arteriosus (PDA) of 223 (34.5\%) babies. Thirdly $102(15.8 \%)$ cases had ventral septal defect (VSD).

Nearly 158(24.5\%) newborns had pulmonary arterial hypertension (PAH) which is measured using tricuspid regurgitation jet measurement in Doppler study. Mild PAH is defined as TR gradient between $35-45 \mathrm{mmHg}$, moderate PAH 45-55 mmHg and severe PAH $>55 \mathrm{mmHg}$ pressure gradient across tricuspid regurgitation jet. Among which 108 babies had mild PAH, 33 babies had moderate PAH, 17 babies had severe PAH. Other echocardiographic findings in present study was 42 newborns had dilated right chambers which was defined by diameter of right ventricle is more than left ventricle after one week of life, few babies(17) had trivial tricuspid regurgitation [8].

Among cyanotic congenital heart diseases, Tetralogy of fallot (TOF) was found in 5 cases, rhabdomyoma and cardiac mass in 4 cases, transposition of great arteries ( 2 cases), partial anomalous venous return (PAPVC in 2 cases), double outlet right ventricle (DORV 2 cases), dextrocardiain 2 cases, bicuspid aortic valve 2 cases. tricuspid atresia, pulmonary atresia,truncus arteriosis, AV canal defect, coarctation of aorta, mitral valve prolapse, pulmonary stenosis with right ventricular hypertrophy, asymmetrical septal hypertrophy, cardiomyopathy, non obstructive cardiomyopathy and hypoplastic left heart syndrome each had 1 case. (table 1)

Table-1: distribution of study subjects according to different diagnosis of CHD.

\begin{tabular}{|c|c|c|}
\hline & Frequency(n=645) & percentage \\
\hline ASD & 326 & $50.4 \%$ \\
\hline VSD & 102 & $15.8 \%$ \\
\hline PDA & 223 & $34.5 \%$ \\
\hline PAH & 158 & $24.5 \%$ \\
mild & 108 & \\
moderate & 33 & \\
severe & 17 & $6.5 \%$ \\
Dilated right chamber & 42 & $0.77 \%$ \\
TOF & 5 & $2.63 \%$ \\
Mild TR & 17 & $4.65 \%$ \\
others & 30 & \\
\hline
\end{tabular}

* Others : Asymmetrical septalhypertropy, bicuspid aortic valve, mitral valve prolapse, cardiac, DORV, tricuspid atresia, pulmonary atresia, TGA, Truncusarteriosus, PAPVC, Rhabdomyoma, dextrocardia, global hypokinesia, AV canal defect, Cardiomyopathy, CoA, PS with RVH, Non obstructive cardimyopathy, HLHS.

Total number of live births during the study period was 15127 , out of which 1020 screened and 520 babies found to have CHD. Total 304 high risk outborns were screened and 125 babies had CHD. Prevalence of CHD was found to be 34.3/1000 live births during study period, which is high, compared with YanjiQu [19] et al.

Risk factors for CHDs: By using univariate logistic all risk factors like sex, preterm, IDM, neonates having severe respiratory distress at birth requiring mechanical ventilator support, bad obstetric history, first trimester fever, consanguineous marriage, folic acid consumption during pregnancy were studied for association with CHDs. By applying univariate logistic regression analysis, the association between sex, pre- term, IDM, Mechanical ventilation, Bad obstetric history, First trimester fever, clinically suspected, consanguineous marriage and Folic acid supplementation with presence of CHD was calculated. presence of CHD was dependent variable (measured dichotomously), sex, Preterm, IDM, Mechanical ventilation, Bad obstetric history, First trimester fever, Clinically suspected, Consanguineous 
marriage and Folic acid supplementation (measured dichotomously or polychotomously) were independent variables. Results were expressed in crude odds ratio with 95\% confidence interval. A statistically significant association was observed between Pre- term, IDM, Mechanical ventilation and Folic acid supplementation with the presence of CHD. (Table 2)

Table-2: Univariate logistic regression.

\begin{tabular}{|c|c|c|c|c|}
\hline & Normal & CHD & Adjusted odds ratio(95\%CI) & P - value \\
\hline Male & 396 & 344 & $1.22(0.98-1.52)$ & 0.068 \\
\hline Female & 283 & 301 & & $<\mathbf{0 . 0 0 1}$ \\
\hline Pre- term & 196 & 250 & $1.55(1.23-1.96)$ & $<\mathbf{0 . 0 1}$ \\
\hline IDM & 28 & 95 & $4.01(2.59-6.21)$ & $<\mathbf{0 . 0 1}$ \\
\hline $\begin{array}{c}\text { Severe respiratory distress } \\
\text { requiring mechanical ventilation. }\end{array}$ & 18 & 53 & $3.28(1.90-5.67)$ & 0.510 \\
\hline Bad obstetric history & 29 & 23 & $0.82(0.47-1.44)$ & 0.716 \\
\hline Firs trimester fever & 46 & 47 & $1.08(0.70-1.64)$ & 0.662 \\
\hline Clinically suspected & 94 & 84 & $0.93(0.67-1.27)$ & 0.051 \\
\hline Consanguineous marriage & 65 & 42 & $0.65(0.43-1.02)$ & $<\mathbf{0 . 0 1}$ \\
\hline Folic acid supplementation & 203 & 51 & $4.52(3.57-6.90)$ & \\
\hline
\end{tabular}

Binominal Logistic Regression Model was applied. Presence of CHD was dependent variable (measured dichotomously), Pre- term, IDM, Mechanical ventilation and Folic acid supplementation (measured dichotomously or polychotomously) were independent variables. The variables that were statistically significant in the univariate logistic regression analysis were included in the binary logistic regression model.

Table-3: Binomial logistic regression.

\begin{tabular}{|c|c|c|c|c|}
\hline & Normal & CHD & Adjusted odds ratio(95\%CI) & P - value \\
\hline Pre- term & 196 & 250 & $1.52(1.16-1.98)$ & $\mathbf{0 . 0 0 2}$ \\
\hline IDM & 28 & 95 & $4.05(2.55-6.43)$ & $<\mathbf{0 . 0 1}$ \\
\hline $\begin{array}{c}\text { Severe respiratory distress } \\
\text { requiring mechanical ventilation. }\end{array}$ & 18 & 53 & $3.51(1.99-6.19)$ & $<\mathbf{0 . 0 1}$ \\
\hline Folic acid supplementation & 203 & 51 & $4.96(3.57-6.90)$ & $<\mathbf{0 . 0 1}$ \\
\hline
\end{tabular}

LR chi2 $(4)=162.99$ Prob $>$ chi2 $=<0.001$ Log likelihood $=-835.79431$ Pseudo $22=.0888$

From the (table 3), Pre- term, IDM, Mechanical ventilation and Folic acid supplementation were statistically significant and may be considered as independent factors for the development of CHD. Pre-term infants were 1.52 times likely to develop CHD when compared to term infants. IDM were 4.05 times likely to develop CHD when compared to non IDM. Infants who had severe respiratory distress requiring prolonged mechanical ventilation were 3.51 times likely to have CHD compared to normal infants. Infants of the mothers who took folic acid supplementation were 4 times less likely to develop CHD when compared to infants of the mothers who did not take folic acid supplementation.

\section{Discussion}

In the present study we found 645 (49\%) babies having CHD out of 1324 high risk newborn screened. Among 645 CHDs majority i.e. 610 (94.6\%) were acynotic heart diseases and only 5.4\% (35 cases) were cyanotic heart diseases which was not similar to other studies because other studies have screened babies up to 18 years $[9,10,11,12]$. Atrial septal defect was in 326 $(50.5 \%)$ cases, patent ductus arteriosis 223(34.5\%) cases, ventricular septal defect $102(15.8 \%)$ cases.
Other studies found $>20 \%$ of cyanotic heart diseases. Higher incidence of cyanotic heart defect in other studies attributed for wide age group screened. Ishikawa $\mathrm{T}$ [16] et al showed overall prevalence of CHD in this series was 50.3 per 1000 live births but the prevalence of newborns with CHD who had signs or symptoms of $\mathrm{CHD}$ and/or required invasive intervention was 21.3 per 1000 live births. Present study also showed 34.3/1000 live births 
In present study there was slight male predominance; 344:301 was male to female ratio i.e. 1.14:1. Result was similar to that of Hussain [9] et al and Kumar [11] et al who had ratio of 2.08:1 and 1.78:1 respectively.

In the present study majority of high risk newborns were preterm. Among 446 preterm babies screened 250 babies were detected to have congenital heart defects with odds ratio of $1.55(1.23-1.96)$ at $95 \%$ CI. In binomial logistic regression model we found preterm infants were 1.52 times likely to develop CHD when compared to term babies. Dulskiene V [17] et al found infants born before 37 weeks of gestation had a 4-fold increased risk $(\mathrm{OR}=4.08$; 95\% CI, 2.68-6.19) compared with newborns born after 37 weeks of gestation.

In the present study retrospective analysis was done about preconception and antenatal consumption of folic acid in reducing incidence of CHDs. We found among 254 mothers of high risk newborns who had consumed folic acid only 51 babies developed CHD with odd ratio of 4.96 (3.57-6.90) i.e. 4.68 less times likely to develop CHD. Shaad Abqari [18] et al found that mothers who had taken multivitamin and folic acid during first trimester had reduced risk of CHDs (OR, 2.853; 95\% CI, 2.089-3.895). In Hungarian randomized trial [13] and population based study in Atlanta [14] showed that mothers who took multi vitamin and folic in first trimester had risk for developing CHD was reduced to $60 \%$ and $25 \%$ respectively.

In the present study among 123 infants of diabetic mother 95 babies had CHD with odd ratio of 4.05(2.55$6.43)$ which statistically very significant. IDM babies are 4 times more like to have CHD compared to other newborn babies.

In the present study babies who had severe respiratory distress at birth requring mechanical ventilation support were screened for CHD after stabilizing, odds ratio of having CHD to be 3.51(1.99- 6.19), which was statistically significant. They were 3.51 times higher risk for having underlying CHD compared to normal babies.

In the present study odds of having CHD to be 0.82 (0.47-1.44) with an underlying bad obstetric history which was similar to Hasan [15] et al found no such association. Odds of having CHD to be 0.65 (0.43-1.02) for consanguineous marriage and odd ratio of 1.08 (0.70- 1.64) for first trimester fever in mother, which were statistically not significant.

\section{Conclusion}

The profile of CHD in newborn period was not well studied in our country due to poor access for 2D echocardiography facility in peripheral regions. It is very important to screen high-risk newborns for underlying CHD because we found nearly $49 \%$ of them had CHD. Present study also found significant association between preterm babies, infants of diabetic mother, babies who have severe respiratory distress requiring mechanical ventilation support were significantly associated with underlying CHD. Consumption of folic acid preconception and during antenatal period is found to be protective in preventing development of CHDs. Therefore we need to prioritize antenatal care and counseling pregnant mothers for folic acid supplementation and strict early screening for gestational diabetes and early control of it. There is need to address preterm deliveries as they have high chances for developing CHD.

Limitation of study: Data are not true representative of profile of CHD in newborn period as only high risk newborns were screened for CHD and therefore true prevalence cannot be predicted. Many preterm babies and severe respiratory distress babies on mechanical ventilators died before stabilizing and screening for CHD.

Funding: Nil, Conflict of interest: None initiated, Perission from IRB: Yes

\section{References}

1. Dolk H, Loane M, Garne E; European Surveillance of Congenital Anomalies (EUROCAT) Working Group. Congenital heart defects in Europe: prevalence and perinatal mortality, 2000 to 2005. Circulation. 2011 Mar1;123(8):841-9.doi:10.1161/ CIRCULATIONAHA. 110.958405. Epub 2011 Feb 14

2. Saxena A. Congenital heart disease in India: a status report. Indian J Pediatr. 2005 Jul;72(7):595-8.

3. Bhat NK, Dhar M, Kumar R, Patel A, Rawat A, Kalra BP. Prevalence and pattern of congenital heart disease in Uttarakhand, India. Indian J Pediatr. 2013 Apr; 80(4): 281-5. doi: 10.1007/s12098-012-0738-4. Epub 2012 Apr 11.

4. Smitha R, Karat SC, Narayanappa D, Krishnamurthy B, Prasanth SN, Ramachandra B, et al. Prevalence of congenital heart diseases in Mysore. Indian $\mathrm{J}$ Hum Genet.2006;12:11-6. 
5. Kumar RK. Universal heart coverage for children with heart disease in India.Ann PediatrCardiol. 2015; 8: 177-83.

6. DC Dutta, HiralalKonar. Meconium Aspiration Syndrome. Text book of obstetrics including Perinarology and Contracepation. Seventh Edition. 2013 Nov; 477.

7. Renu Mishra. Ian Donalds Practical Obstetric Problems. Seventh edition. 2013;86.

8. Mertens L, Seri I, Marek J, Arlettaz R, Barker P, McNamara P, Moon-Grady AJ, Coon PD, Noori S, Simpson J, Lai WW. Targeted Neonatal Echocardiography in the Neonatal Intensive Care Unit: practice guidelines and recommendations for training. Writing Group of the American Society of Echocardiography (ASE) in collaboration with the European Association of Echocardiography (EAE) and the Association for European Pediatric Cardiologists (AEPC). J Am Soc Echocardiogr. 2011 Oct; 24 (10): 1057-78. doi: 10.1016/j.echo.2011.07.014.

9. Hussain M, Tahura S, Sayeed MA, Rahman MM, Rahman MM, Kar SK. Past and present pattern of congenital heart disease at DSH: A situation analysis. Bangladesh J Child Health.2010;34:51-5.

10. Amro K. Pattern of congenital heart disease in Jordan. Eur J Gen Med. 2009;6:1615.

11. Kumar BD, Reddy KR, Elizabeth B. Study of incidence of congenital heart diseases in children of age group 1 month to 12 yrs. J Evol Med Dental Sci. 2015; 4:1151-9.

12. Khan I, Muhammad A, Muhammad T. Pattern of congenital heart disease. Gomal $\mathrm{J}$ of Med Sci. 2011;9:174-7.
13. Botto LD, Mulinare J, Erickson JD. Occurrence of congenital heart defects in relation to maternal mulitivitamin use. Am J Epidemiol. 2000 May 1;151 (9): 878-84.

14. Scanlon KS, Ferencz C, Loffredo CA, Wilson PD, Correa-Villasenõr A, Khoury MJ, Willett WC. the Baltimore-Washington Infant Study Group. Preconceptional and folate intake and malformations of the cardiac outflow tract. Epidemiology. 1998; 9:95-8. [PubMed]

15. Hassan I, Haleem AA, Bhutta ZA. Profile and risk factors for congenital heart disease. J Pak Med Assoc. 1997 Mar;47(3):78-81.

16. Ishikawa T, Iwashima S, Ohishi A, Nakagawa Y, Ohzeki T. Prevalence of congenital heart disease assessed by echocardiography in 2067 consecutive newborns. Acta Paediatr. 2011 Aug;100(8):e55-60. doi: 10.1111/j.1651-2227.2011.02248.x. Epub 2011 Mar 24.

17. Dulskiene V,Malinauskiene V, Azaraviciene A, Kuciene R. [The incidence and diagnostics of congenital heart defects in Kaunas infant population during 1999-2005]. Medicina (Kaunas) 2008; 44 (2): $139-146$

18. ShaadAbqari, Akash Gupta, TabassumShahab, MU Rabbani, S Manazir Ali, and UzmaFirdaus. Profile and risk factors for congenital heart defects: A study in a tertiary care hospital Ann PediatrCardiol. 2016 SepDec; 9(3): 216-221. doi: 10.4103/0974-2069.189119.

19. Qu Y, Liu X, Zhuang J, Chen G, Mai J, Guo X, Ou Y, Chen J, Gong W, Gao X, Wu Y, Nie Z. Incidence of Congenital Heart Disease: The 9-Year Experience of the Guangdong Registry of Congenital Heart Disease, China. PLoS One. 2016 Jul 13;11(7):e0159257. doi: 10.1371/journal.pone.0159257. eCollection 2016.

\section{How to cite this article?}

Devadas S, Gagandeep V.L, Nagabhushan B.M, Pavitra N.A, Ranjitha R, Pruthvi S. Screening of high risk neonates for congenital heart defects: A study in level III neonatal intensive care unit. J PediatrRes. 2017; 4(02):176181.doi:10.17511/ijpr.2017.i02.15. 